\title{
ÁCIDO CLAVULÂNICO E CEFAMICINA C: UMA PERSPECTIVA DA BIOSSÍNTESE, PROCESSOS DE ISOLAMENTO E MECANISMO DE AÇÃO
}

\author{
Jaine H. H. Luiz de Oliveira*, Ana Claudia Granato, Daniela B. Hirata, Carlos O. Hokka e Marlei Barboza \\ Departamento de Engenharia Química, Universidade Federal de São Carlos, Rod. Washington Luiz, km 235, 13565-905 São \\ Carlos - SP, Brasil \\ Milan Trsic \\ Instituto de Química de São Carlos, Universidade de São Paulo, CP 780, 13560-970 São Carlos - SP, Brasil
}

Recebido em 27/10/08; aceito em 5/5/09; publicado na web em 20/10/09

\begin{abstract}
CLAVULANIC ACID AND CEPHAMICIN C: A PERSPECTIVE OF THE BIOSYNTHESIS, ISOLATION AND ACTION MECHANISM. The present article reviews different aspects of the chemistry of two widely used $\beta$-lactam antibiotics Clavulanic Acid and Cephamycin C. The article discusses important details of the biosynthesis of these compounds, their action mechanism and, principally, the methods employed in their isolation and purification, in accordance with the available literature. Despite the large quantity of available articles and patents concerning $\beta$-lactam antibiotics, those which describe the isolation and purification of Clavulanic Acid and Cephamycin C are rare. Overall, the intention of this article is to discuss the up-to-date scientific research related to the compounds under review.
\end{abstract}

Keywords: $\beta$-lactam antibiotics; clavulanic acid; cephamycin C.

\section{INTRODUÇÃO}

Antibióticos são metabólitos secundários produzidos por microrganismos ou por organismos específicos, que em quantidades pequenas são capazes de inibir o desenvolvimento de patógenos e, portanto, são usados no combate às infecções em seres humanos e animais. ${ }^{1}$ Dos antibióticos produzidos por microrganismos $66 \%$ são de actinomicetos, $22 \%$ de fungos e $12 \%$ de outras bactérias. Dentre os actinomicetos, $80 \%$ são obtidos a partir do gênero Streptomyces. ${ }^{2}$

A história das penicilinas se iniciou com Alexander Fleming em 1928, ao notar em um de seus experimentos com cultura de bactérias, que havia ficado exposta ao ar durante semanas, uma contaminação por fungos. Em seu experimento verificava-se que certa área da colônia de bactérias ao redor da colônia de fungos estava morrendo. Fleming concluiu que a colônia de fungos estava produzindo algum agente antibacteriano que estava se espalhando ao redor da colônia com o objetivo de se proteger. Posteriormente, Fleming identificou a colônia como sendo uma espécie rara de Penicillium. ${ }^{3}$

Durante anos, Fleming dedicou-se ao trabalho de isolar e identificar o agente antibacteriano produzido pelo fungo em sua colônia de bactérias, entretanto a substância mostrou-se muito instável e seu propósito não foi alcançado, concluindo que o composto seria instável demais para ser utilizado clinicamente. ${ }^{3}$ Mais tarde, em 1938, Florey e Chain chegaram ao extrato bruto contendo a penicilina, que após 3 anos foi testada clinicamente obtendo-se grande sucesso. ${ }^{3}$ Por este trabalho, Fleming, Florey e Chain dividiram o Prêmio Nobel de Medicina em 1945. A penicilina G (Figura 1), produzida por fungos do gênero Penicillium, foi o primeiro antibiótico a se tornar disponível para uso clínico em 1942, lembrando que sua descoberta remonta o final dos anos 20.

Esse composto revolucionou o tratamento de uma grande variedade de infecções, dentre elas, a febre escarlate, a pneumonia, a gonorréia e sérias infecções causadas por bactérias do gênero Staphylococcus, as quais, até então, não possuíam tratamento. Após muita investigação, observou-se que havia muitos derivados naturais

*e-mail: jainehh@gmail.com da penicilina que eram letais a uma grande variedade de bactérias Gram-positivas, contudo, certas classes de bactérias Gram-positivas eram resistentes ao efeito das penicilinas e estas apresentavam baixa atividade contra bactérias Gram-negativas. ${ }^{3,4}$ Existem diversos aná$\operatorname{logos}$ da penicilina onde a diferença reside na cadeia lateral ligada ao anel $\beta$-lactâmico.
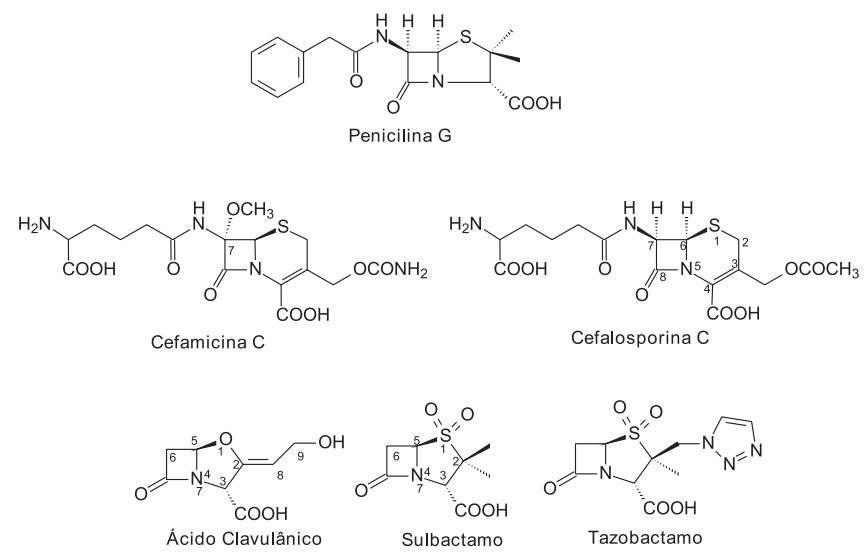

Figura 1. Estrutura dos antibióticos $\beta$-lactâmicos e dos inibidores de $\beta$ lactamase

O segundo grupo de antibióticos a ser isolado foi o das cefalosporinas. A primeira cefalosporina obtida foi a cefalosporina $\mathrm{C}$ (Figura 1) isolada por Brotzu em 1948, a partir do fungo Cephalosporium acremonium. Entretanto, apesar de sua forte atividade contra certas bactérias Gram-negativas ter sido descoberta no mesmo ano de seu isolamento, sua estrutura só foi determinada em 1961. ${ }^{4}$ Assim como para as penicilinas, existem vários análogos da cefalosporina $\mathrm{C}$ onde há variação na cadeia lateral 3-acetoximetil.

A família dos antibióticos $\beta$-lactâmicos constitui o grupo mais importante dentre esses fármacos, tanto em relação à sua utilização clínica quanto do ponto de vista econômico. Esses antibióticos podem ser subdivididos em 5 grupos, ${ }^{5}$ como mostra a Tabela 1 . 
Tabela 1. Divisão dos grupos de antibióticos $\beta$-lactâmicos

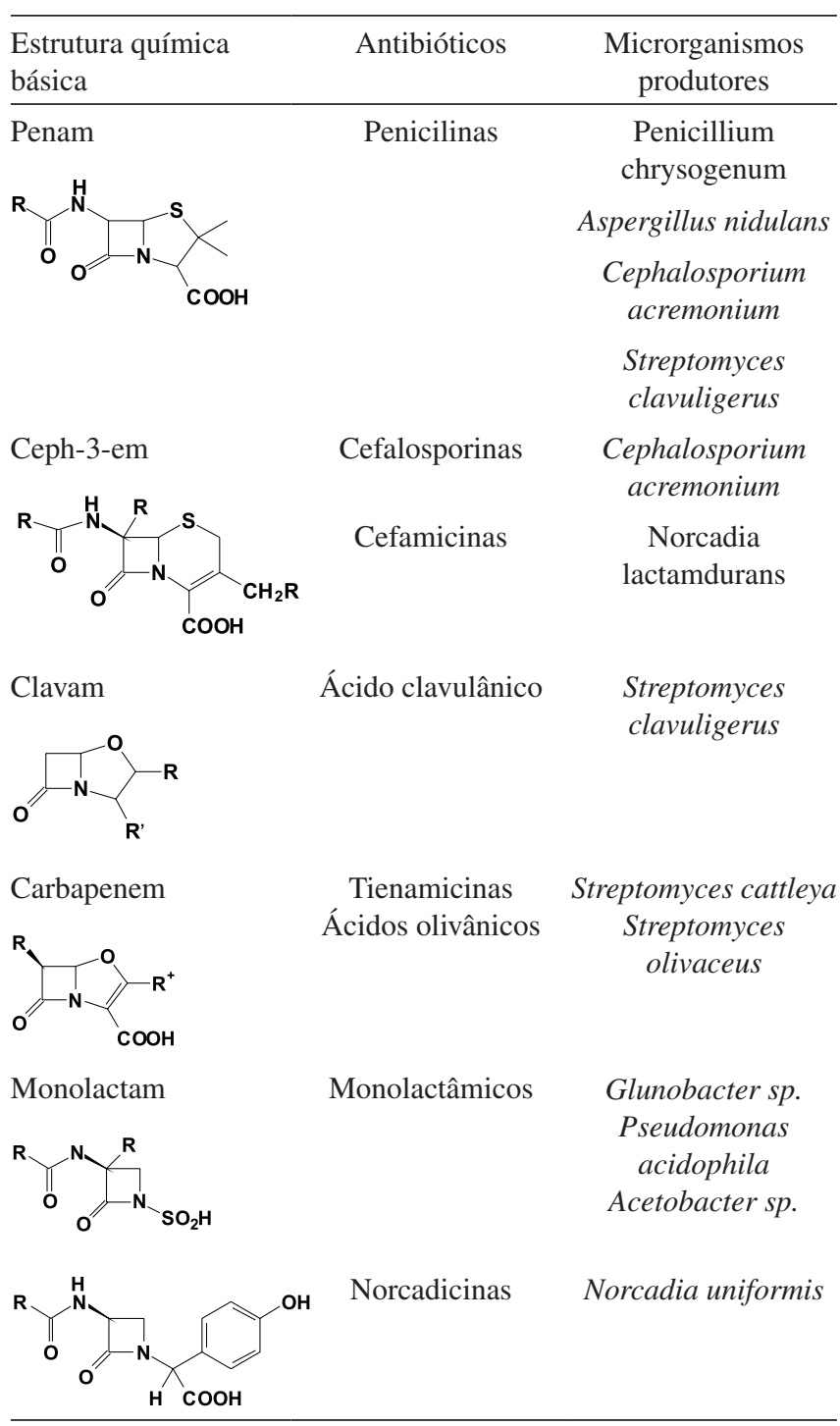

A produção industrial de antibióticos $\beta$-lactâmicos por fermentação nos últimos 50 anos é um grande exemplo de utilização de biotecnologia; as penicilinas e cefalosporinas representam um mercado de 15 bilhões de USD, correspondendo a $65 \%$ do mercado global de antibióticos, sendo que 9,9 bilhões são devidos a cefalosporinas e cefamicinas. ${ }^{6}$

Desde a introdução destes antibióticos, muitos outros derivados $\beta$-lactâmicos com atividade antibiótica superior foram colocados no mercado, porém a eficiência destes fármacos tem sido ameaçada pelo crescente número de bactérias capazes de inativá-los. ${ }^{7}$ Estes microrganismos, através de suas enzimas $\beta$-lactamases, catalisam a hidrólise do anel $\beta$-lactâmico do antibiótico, originando um produto inativo, isto é, sem ação antibiótica.

Em 1967, no Beecham Research Laboratories iniciou-se um programa de triagem de microrganismos, com a finalidade de isolar inibidores de $\beta$-lactamases de ocorrência natural, que permitiu o isolamento do ácido clavulânico (AC-Figura 1) a partir de Streptomyces clavuligerus,${ }^{8}$ o qual foi descrito pela primeira vez em 1976 por Brown e seu grupo de pesquisa. ${ }^{9}$

Também são conhecidos outros dois compostos inibidores de $\beta$-lactamases, o sulbactamo e o tazobactamo (Figura 1), porém de origem sintética. Estes são estruturalmente parecidos, diferenciando-se apenas na adição de um grupo triazol no grupo $\beta$-metil do carbono $\mathrm{C} 2$ no tazobactamo. Ambos os compostos podem ser encontrados em formulações disponíveis comercialmente com os nomes de Unasyn (ampicilina/sulbactamo) e Zosyn (piperacilina/ tazobactamo). Nos Estados Unidos, as formulações comerciais contendo estes compostos são: Superazone (cefoperazona/sulbactamo), Sultamicilina (ampicilina/sulbactamo) e Tazocin (piperacilina/ tazobactamo), sendo este último comercializado pela Wyeth e responsável por uma venda anual de 1 bilhão de dólares..$^{10} \mathrm{O}$ mecanismo de inibição tanto para o sulbactamo quanto para o tazobactamo é parecido com o do AC. ${ }^{11}$ Entretanto, segundo Payne et al.,${ }^{12} \mathrm{o}$ ácido clavulânico apresenta atividade inibidora de enzimas $\beta$-lactamase quase 5 vezes maior que o tazobactamo e quase 600 vezes maior que o sulbactamo (ácido clavulânico $=0,03 \mu \mathrm{M}$; tazobactamo $=0,14$ $\mu \mathrm{M}$; sulbactamo $=17 \mu \mathrm{M})$.

Até o momento tudo o que foi descrito tem uma abrangência mundial, porém o mesmo não se aplica ao Brasil. Isso porque, dentre as estratégias para diminuir os preços dos medicamentos, a substituição da importação pela produção local é, sem dúvida, uma das mais importantes. Mas se é verdade que a indústria nacional farmacêutica cresceu significativamente na década de 90, respondendo hoje por aproximadamente $90 \%$ do que é consumido no país (dados da Associação Brasileira da Indústria Farmoquímica - Abiquif), o contrário se deu para a indústria farmoquímica, responsável pela fabricação dos princípios ativos e intermediários, cujo desenvolvimento foi praticamente nulo. Atualmente, $82 \%$ dos farmoquímicos utilizados na fabricação de medicamentos são ainda importados, segundo os dados da Abiquif. ${ }^{13}$ Hoje, a atividade do setor farmacêutico no Brasil consiste em misturar os componentes para dar a forma final de apresentação aos medicamentos.

Resolver a disparidade entre as indústrias farmacêutica e farmoquímica está no centro das discussões sobre o crescimento do setor de fármacos no Brasil. A necessidade de atuação do governo, através de uma política de incentivo à pesquisa e desenvolvimento e de incentivo à indústria nacional, é apontada como requisito para solucionar o problema. ${ }^{13}$

A integração entre todos os setores é vista como fundamental, uma vez que o número de importações de princípios ativos e medicamentos é muito maior do que a quantidade de exportações pelo Brasil.

\section{ÁCIDO CLAVULÂNICO (AC)}

O AC é constituído por um anel $\beta$-lactâmico condensado a um anel oxazolidina, apresenta baixa atividade antibiótica, mas é um poderoso e irreversível inibidor de enzimas $\beta$-lactamases produzidas por bactérias resistentes às penicilinas e cefalosporinas. Possui uma estrutura básica clavam e uma estereoquímica característica $2 R, 5 R$, essencial para atuar como uma molécula inibidora de $\beta$-lactamases. ${ }^{14} \mathrm{O}$ AC é o primeiro exemplo de composto natural onde o anel $\beta$-lactâmico não está ligado a um anel contendo enxofre, é capaz de inibir a maioria das $\beta$-lactamases classe $\mathrm{A}$, é pouco ativo contra as cefalosporinases da classe $\mathrm{C}$ e inativo contra metaloenzimas $\mathrm{Zn}^{2+}$ da classe $\mathrm{B} .{ }^{14} \mathrm{Na}$ presença de baixas concentrações de AC, muitas bactérias produtoras de $\beta$-lactamases tornam-se sensíveis às penicilinas e cefalosporinas comercialmente disponíveis. ${ }^{9}$ Quando o AC é utilizado juntamente com estes antibióticos, ocorre uma ligação irreversível entre o grupo hidroxila da serina da $\beta$-lactamase e o AC, produzindo um intermediário estável, inativando a enzima e permitindo, assim, que o outro antibiótico atue no combate à infecção. ${ }^{15}$

A combinação do AC com a amoxicilina é o exemplo de maior sucesso do uso de um antibiótico $\beta$-lactâmico sensível à $\beta$-lactamase, juntamente com um inibidor desta enzima. ${ }^{16}$ Esta combinação é a mais comercializada e gerou 1,3 bilhões de dólares em vendas em 1995, porém, de acordo com Saudagar e colaboradores houve um decréscimo nas vendas desta formulação de 1,6 bilhões em 2001 
para 107 milhões em 2004, o que representa uma perda de $93 \%$ nas vendas em apenas 3 anos. ${ }^{10}$ Antecipando o final da patente do Augmentin, a GSK lançou os produtos Augmentin ES-600 e Augmentin XR. Porém, apesar destes dois produtos ajudarem parcialmente na diminuição da perda em vendas (de 93 para 68\%), a GSK continuou registrando uma queda nas vendas. ${ }^{10}$

A formulação que contém o AC e a amoxicilina é comercializado, no Reino Unido, com o nome Augmentin (DSM Anti Infectives Delft - Holanda) e no Brasil, com o nome Clavulin (Smith Kline Beecham Laboratory - Rio de Janeiro). O processo de obtenção industrial do $\mathrm{AC}$ é pouco documentado na literatura, sendo importante o conhecimento e o melhoramento do seu processo de produção. ${ }^{6}$

Mesmo após 20 anos de uso clínico, a combinação amoxicilina/ AC continua apresentando excelente atividade contra a maioria das espécies de bactérias patogênicas Gram-positivas (Staphylococcus aureus (MSSA), S. epidermidis, Enterococcus faecalis, Streptococcus pyogenes, S. pneumoniae, entre outras) e também contra muitas bactérias Gram-negativas (Haemophilus influenzae, H. parainfluenzae, $M$. catarrhalis, Neisseria gonorrhoeae, Klebsiella pneumoniae, Proteus mirabilis, $P$. vulgaris, entre outras).$^{17}$

Esta combinação é utilizada no combate a diferentes enfermidades com grande eficácia se comparada a outros medicamentos como, por exemplo, no tratamento de infecções do trato respiratório com resposta positiva superior se comparado à azitromicina, cefixima ou ciprofloxacina nos casos de bronquite crônica. ${ }^{18}$

Um estudo realizado com crianças africanas que apresentavam infecções no trato urinário mostrou que a eficácia do antibiótico amoxicilina/AC era de $77,8 \%$ dos casos, enquanto que para a nitrofurantoina era de $67 \% .^{19}$

Estudou-se também a ação do medicamento em osteíte alveolar, ${ }^{20}$ em abscessos endodônticos, ${ }^{21}$ em casos de diarréia, ${ }^{22}$ entre outras doenças, sendo excelentes os resultados para os tratamentos destas infecções quando se utiliza a combinação amoxicilina/AC.

$\mathrm{O}$ aumento de bactérias $S$. pneumoniae resistentes aos antibióticos tem causado grande preocupação nos últimos anos. Em vários estudos realizados notou-se que, embora as CIMs (concentrações inibitórias mínimas) de amoxicilina/AC sejam essencialmente similares àquelas apenas com amoxicilina, existe uma tendência para as CIMs serem menores para a combinação dos antibióticos. Estas diferenças são pequenas, mas testes de CIM in vitro podem não ser suficientemente sensíveis para demonstrar qualquer efeito do clavulanato na atividade da amoxicilina contra $S$. pneumoniae. Estudos in vitro sugerem que o clavulanato pode interferir na atividade $\beta$-lactâmica contra $S$. pneumoniae através de uma ligação complementar às PBPs (proteínas de ligação à penicilina). ${ }^{23,24}$

Atualmente, as companhias que produzem o AC são: Glaxo SmithKline, nos EUA; Sandoz Lek D.D., em Lendava (Eslovênia) e CIPAN, em Portugal. ${ }^{10}$

\section{Biossíntese do ácido clavulânico}

A biossíntese do AC não foi totalmente elucidada, apesar de muitos intermediários e enzimas já terem sido isolados. Os estudos com isótopos, a purificação e caracterização das enzimas que participam do processo juntamente com os estudos genéticos têm contribuído para esclarecer sua rota biossintética.

$\mathrm{Na}$ biossíntese do AC (Figura 2), a arginina e a ornitina exercem uma estimulação dependente da concentração ${ }^{25}$ e ambos os aminoácidos são efetivamente incorporados na molécula de ácido clavulânico. ${ }^{25-27} \mathrm{~A}$ incorporação destes dois aminoácidos acontece nos carbonos C-2, C-3, C-8 e C-10. A incorporação da arginina na molécula de AC não estabelece a ornitina como precursor direto, pois a enzima ornitinacarbamil transferase de $S$. clavuligerus possui atividade arginase, que converte a arginina em ornitina. ${ }^{28}$ No entanto,
Valentine et al. ${ }^{29}$ utilizaram mutantes bloqueadores nos genes $\arg \mathrm{Fe}$ $\arg \mathrm{G}$, os quais foram incapazes de converter a ornitina em arginina e mesmo assim encontraram uma boa incorporação da arginina marcada isotopicamente na molécula de $\mathrm{AC}$ e uma pobre incorporação de ornitina. Isto demonstra que a arginina é o precursor direto do $\mathrm{AC} \mathrm{e}$ indica que a atividade arginase não produz suficiente ornitina para incorporar no AC. Townsend et al. ${ }^{26}$ sugeriram como precursores do $\mathrm{AC}$ a arginina e o piruvato para a formação do AC.
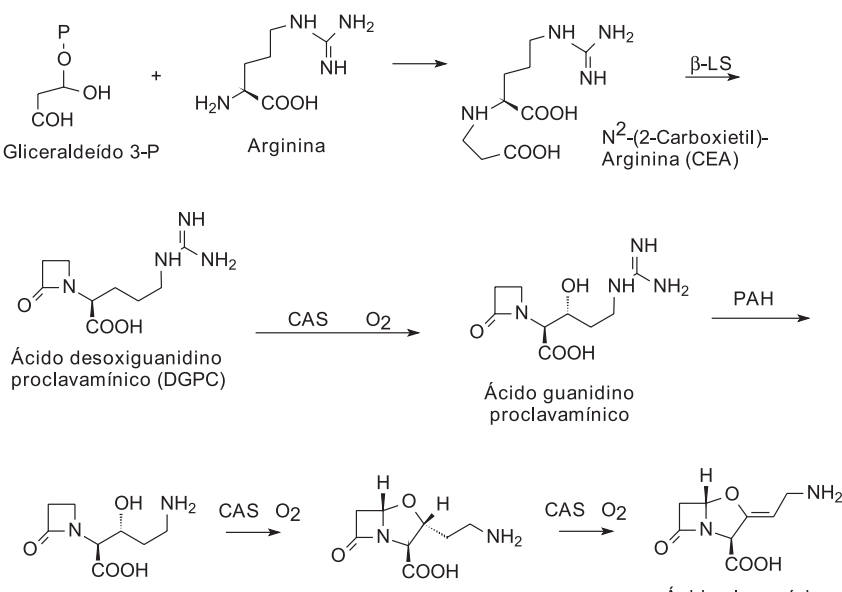

Ácido proclavamínico Ácido diidroproclavamínico Ácido clavamínico

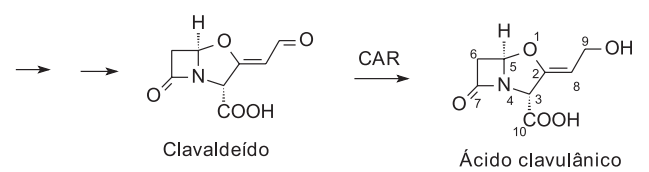

CAS: clavaminato sintase $\quad$ PAH: proclavamínico aminidino hidrolase

$\beta$-LS: beta lactam sintase $\quad$ CAR: clavaldeído redutase ou CAD: ácido clavulânico desidrogenase

Figura 2. Biossíntese do ácido clavulânico

Os ácidos clavamínico e proclavamínico foram os primeiros intermediários isolados de $S$. clavuligerus $^{30} \mathrm{e}$, mais tarde, dois compostos guanidínicos $\mathrm{N}^{2}$-(2-carboxietil)-arginina (CEA) e o ácido desoxiguanidino (DGPC) foram identificados. ${ }^{31}$ Usando o ácido proclavamínico como substrato, a clavaminato sintase (CAS) foi descrita por converter o ácido proclavamínico em ácido clavamínico. ${ }^{14,30} \mathrm{~A}$ purificação da enzima CAS foi realizada por Salowe e colaboradores, em 1990, e revelou que haviam duas formas da mesma enzima, cujas diferenças estavam nas propriedades cinéticas e na massa melecular. Embora a enzima seja capaz de catalisar 3 passos distintos na rota biossintética, não há evidências que suas duas formas diferem na capacidade de catalisar qualquer uma das 3 etapas. ${ }^{32}$ Acredita-se que uma das formas da CAS faça parte da biossíntese do AC, enquanto a outra esteja associada à produção de outros clavams. $\mathrm{O}$ ácido clavamínico difere do AC na estereoquímica do sistema de aneis e esta transformação requer a inversão na estereoquímica do anel, bem como a conversão do substituinte da cadeia lateral de um grupo amino para um grupo hidroxila, porém esta reação ainda não foi esclarecida. A presença de um aldeído intermediário com a mesma estereoquímica do AC demonstra a presença de NADPH, que reduz o clavaldeído através da enzima CAD a ácido clavulânico..$^{33}$

Pouco se conhece sobre a regulação da produção de AC, existindo controvérsias a respeito dos substratos que favorecem ou não a produção do mesmo.

\section{Processos de isolamento e purificação do ácido clavulânico}

O processo de separação e purificação do $\mathrm{AC}$ a partir do meio de fermentação envolve uma série de etapas, como filtração e centrifuga- 
ção para a separação de células e técnicas de extração e/ou adsorção para posterior purificação do antibiótico. Porém, o AC apresenta velocidades de degradação elevadas em temperaturas acima de 30 ${ }^{\circ} \mathrm{C}$, em regiões básicas $\mathrm{pH}>7,5$ e em regiões ácidas $\mathrm{pH}<4,5 .{ }^{34,35}$ Isso leva a baixos rendimentos durante os processos de purificação, quando comparados a outros compostos $\beta$-lactâmicos. ${ }^{36}$

Muitos autores investigaram a estabilidade do AC em soluções tampão em diferentes valores de $\mathrm{pH}$. Estes autores observaram que a degradação do AC segue uma cinética de pseudoprimeira ordem e que esta degradação é muito influenciada pela catálise causada pelos sais do tampão utilizados para manter constante o $\mathrm{pH} .{ }^{35}$

Haginaka e colaboradores concluíram, em seu estudo de degradação utilizando temperaturas de 35,60 e $100{ }^{\circ} \mathrm{C}$, que a máxima estabilidade para o AC ocorre a $35{ }^{\circ} \mathrm{C}$, com uma força iônica igual a $\mu=0,5$ e em $\mathrm{pH}=6,39$. Além disso, concluíram que a constante de velocidade de degradação aumenta com o aumento da concentração do tampão. ${ }^{37}$ Os autores também constataram que a degradação do $\mathrm{AC}$ em meio neutro e ácido é diferente da degradação que ocorre em meio básico. Os mesmos autores estudaram a degradação do $\mathrm{AC}$ em solução aquosa levemente alcalina a várias temperaturas e identificaram quatro produtos de degradação (Figura 3) que são a 2,5-bis-(2-hidroxietil)pirazina (I), 3-metil-2,5-bis-(2-hidroxietil) pirazina (II), 3-(2-carboxietil)-2,5-bis-(2-hidroxietil)pirazina (III) e a 3-etil-2,5-bis-(2-hidroxietil)pirazina (IV). À temperatura de 35 ${ }^{\circ} \mathrm{C}$ não é observada a formação do produto II, mas a $60{ }^{\circ} \mathrm{C}$ todos os produtos foram observados e a $100^{\circ} \mathrm{C}$ o produto III não é formado. ${ }^{38}$
Pirazinas<smiles>[R]c1nc(CCO)cnc1CCO</smiles>

(I): $\quad \mathrm{R}=\mathrm{H}$
(II): $\mathrm{R}=\mathrm{CH}_{3}$

(III): $\mathrm{R}=\mathrm{CH}_{2} \mathrm{CH}_{2} \mathrm{COOH}$

(IV): $\mathrm{R}=\mathrm{CH}_{2} \mathrm{CH}_{3}$

Figura 3. Produtos de degradação do ácido clavulânico

O trabalho realizado por Finn e colaboradores ${ }^{39}$ identificou e caracterizou o produto majoritário resultante da hidrólise do $\mathrm{AC}$ em meio ácido como sendo uma amino cetona. Em condições ácidas, a amino cetona pode ser estável, entretanto em soluções neutras ou básicas pode-se esperar que este composto sofra uma reação de condensação intermolecular, formando uma pirazina.

Bersanetti e colaboradores concluíram que a estabilidade do AC a $20{ }^{\circ} \mathrm{C}$ e $\mu=0,5$ é maior em $\mathrm{pH}=6,0$ e que a degradação ocorre mais rapidamente em soluções básicas do que em soluções ácidas. ${ }^{34}$ Verificaram também que as constantes de degradação do AC em soluções aquosas são menores em relação às soluções obtidas do meio de fermentação, isto devido à presença de outros componentes do meio, tal como compostos que contêm amônio. ${ }^{35}$

Muitas patentes ${ }^{40-42}$ descrevem que o AC pode ser extraído do caldo de fermentação por diferentes métodos. O primeiro passo é remover as células do meio, o que é realizado através de filtração ou centrifugação. Em seguida, é feita uma extração com solvente orgânico após abaixar o pH da solução aquosa entre 2-3 através da adição de ácido, sob agitação. Estas patentes sugerem vários solventes orgânicos como acetato de etila, n-butanol, metilisobutilcetona, acetato de n-butila, entre outros. Depois da separação das fases, o AC, presente na fase orgânica, é re-extraído com uma nova fase aquosa onde podem ser utilizados tampão fosfato, solução de bicarbonato de sódio, carbonato de cálcio ou apenas água, mantendo o pH próximo de 7. O extrato aquoso pode ser concentrado à pressão reduzida e liofilizado. O sal obtido é estável quando armazenado como um sólido seco a $-20^{\circ} \mathrm{C}$. Para sua purificação pode-se utilizar resina de troca iônica do tipo Amberlite IR4B ou Zerolite FFIF, até a saturação da resina, a qual deve ser lavada com água e com solução de $\mathrm{NaCl}$ para eluir o AC.

Essas patentes sugerem também que o AC ou o seu sal clavulanato pode ser convertido em um éster, através de uma reação de esterificação, podendo ser purificado em seguida por cromatografia de permeação em gel Sephadex LH20, utilizando-se como eluentes uma mistura de cicloexano e clorofórmio (1:1) e por cromatografia em Si gel utilizando como eluente cicloexano e acetato de etila (1:1). O éster obtido pode ser convertido em clavulanato de sódio ou potássio, através de uma reação de hidrogenólise utilizando como catalisador $10 \% \mathrm{Pd} / \mathrm{C}$ em solução de $\mathrm{NaHCO}_{3}$ e etanol. A recuperação do sal é feita por cristalização.

As patentes Fleming et $a l .{ }^{43,44}$ sugerem que a purificação do AC deve ser feita pela sua conversão em clavulanato de lítio com subsequente precipitação, a qual geralmente ocorre na forma cristalina. Esta precipitação é possível devido a grande afinidade dos íons clavulanato pelos cátions lítio, juntamente com insignificante coprecipitação de impurezas. Diminuindo-se a temperatura para cerca de $0-5{ }^{\circ} \mathrm{C}$, diminui-se também a solubilidade do clavulanato, o qual alcançará uma máxima precipitação em baixas temperaturas. A adição de solventes orgânicos, como acetona, metanol, etanol etc, contribui para a precipitação. A purificação do AC é complexa devido à presença de compostos com propriedades e comportamento similares ao AC.

As patentes Cook, ${ }^{45} \mathrm{Kim}$ et al. ${ }^{46}$ e Cardoso ${ }^{47}$ descreveram a precipitação do AC com o sal 2-etilexanoato de potássio ou sódio, como uma das etapas no processo de purificação do AC presente no meio de fermentação. Uma etapa de extração com solvente orgânico é realizada e a fase orgânica é submetida a uma reação de precipitação, na qual ocorre a precipitação do AC com o 2-etilexanoato de potássio (sódio) com formação do sal clavulanato de potássio (sódio). Contudo, a reação direta do AC com o sal 2-etilexanoato de potássio muitas vezes não é favorecida, ocasionando formação de óleo e não do produto desejado, na forma de cristal.

Outras patentes, como Capuder, ${ }^{48-50}$ Simon, ${ }^{51}$ e Callewaert ${ }^{52}$ sugerem uma etapa intermediária, visando diminuir a instabilidade da reação citada através da formação de um sal de amina do AC como intermediário, o isolamento deste intermediário e sua conversão em AC geram um composto com alto teor de pureza. Entretanto, Kim et $a l .{ }^{46}$ descreveram que, em geral, a maioria das aminas é inadequada para a manufatura do sal de clavulanato, ou usadas como intermediárias, pois estes sais de amina são tóxicos e higroscópicos, e que também necessitam de grandes quantidades de solventes para que ocorra sua solubilização para a reação posterior, dando origem ao clavulanato de potássio.

Butterworth $^{53}$ descreveu dois métodos de purificação do AC a partir de caldos de fermentação. No primeiro, o caldo tem seu $\mathrm{pH}$ reduzido e a extração do AC é feita com solvente orgânico. A fase orgânica é re-extraída com solução de $\mathrm{NaOH}$ em pH 7. O extrato obtido é aplicado em uma resina Amberlite XAD-4 para desmineralizar o meio, sendo então obtido o clavulanato de sódio. No segundo método, o caldo é aplicado em uma resina de troca aniônica e eluído com solução salina, seguindo-se as etapas de adsorção em resina XAD-4 e Zerolite SRA 62. Segundo o autor, o meio é desmineralizado em resina XAD-4. O produto final apresenta alto teor de pureza e é obtido por liofilização ou por cristalização na solução aquosa.

Mayer et al. ${ }^{16}$ estudaram o uso de resina Amberlite XAD para a purificação do AC a partir do caldo fermentado. Foi observada uma fraca interação entre o ácido clavulânico e a superfície apolar das resinas. Estas resinas foram testadas em combinação com sais de amônio quaternário com diferentes polaridades e formando pares iônicos com o grupo ácido da molécula de AC. Os autores concluíram que a cromatografia com formação de par iônico é uma alternativa eficiente na purificação do AC e que a resina Amberlite XAD-4 com 
sais de amônio quaternário é mais eficiente em relação à IRA 400.

Um sistema de duas fases aquosas, constituído de polietileno glicol (PEG) e tampão fosfato, foi desenvolvido por Videira et al. ${ }^{54}$ para extração e purificação do AC. Observou-se que o clavulanato de potássio apresenta grande afinidade pela fase rica em PEG com elevados coeficientes de partição. $\mathrm{O}$ estudo foi realizado com PEG de diferentes massas moleculares e em diferentes valores de $\mathrm{pH}$. Foi observado que o coeficiente de partição do AC é maior em $\mathrm{pH}$ 8 , porém sua degradação neste $\mathrm{pH}$ é maior. Até o momento não se conhece uma maneira de re-extrair o AC do PEG.

Brites et al. ${ }^{55}$ compararam dois diferentes métodos de extração do AC do caldo de fermentação, a extração por solvente orgânico e por sistema de duas fases aquosas (SDFA). Na extração por solvente orgânico, vários solventes foram estudados, como acetato de etila, acetato de butila, metilisobutilcetona, n-butanol e 2-butanol em diferentes pHs (de 2 a 5). Os sistemas de duas fases aquosas eram compostos por PEGs de massas moleculares diferentes $(6000,4000$, 1000,400 e 600), soluções fosfato em dois valores de $\mathrm{pH}(6,0$ e 7,0). Os dois métodos foram comparados, utilizando-se o coeficiente de partição, os fatores de concentração e de purificação e o rendimento.

Os melhores resultados para o solvente orgânico foram a $\mathrm{pH} 2$, pois a constante de ionização do AC é de 2,25. O melhor solvente em termos de coeficiente de partição foi o n-butanol $(1,37)$, seguido do 2-butanol $(0,91)$ e acetato de etila $(0,58)$. Para os sistemas de duas fases aquosas o melhor coeficiente de partição ficou com o PEG 600 e PEG 6000 (15,5); em relação aos fatores de purificação e concentração, os melhores resultados foram para o n-butanol.

Silva et $a l .{ }^{56}$ fizeram um estudo envolvendo a otimização da extração de AC usando SDFA. Os autores utilizaram um modelo experimental que permitiu avaliar o efeito de cada parâmetro no coeficiente de distribuição, fator de purificação e rendimento, para que fosse possível otimizar os parâmetros de processo, determinando assim as melhores condições de purificação. Para a extração do AC do caldo de fermentação por SDFA, o melhor rendimento ficou entre $90-100 \%$ e o fator de purificação entre 1,5-2,0. Os quatro parâmetros que alcançaram um nível ótimo de rendimento e fator de purificação foram PEG 400, pH 6,4, TLL (tie line length) 42 e rTTL (tie-line ratio) 1,3 correspondente a um SDFA com rendimento de cerca de $100 \%$ e fator de purificação de 1,5 para o AC. Estes resultados indicaram que o SFDA é uma alternativa viável para a purificação do AC, podendo ser integrada a outras operações de purificação como ultrafiltração, troca iônica ou mesmo reações de precipitação.

Hirata et al..$^{57}$ descreveram detalhadamente a reação citada em patentes sobre a precipitação do ácido clavulânico proveniente do caldo de fermentação utilizando o sal 2-etilexanoato de potássio. Examinaram a influência de diferentes concentrações de AC em diferentes concentrações de sal 2-etilexanoato de potássio durante as reações de precipitação e verificaram que a concentração combinada de $15 \mathrm{mg} / \mathrm{mL}$ de $\mathrm{AC}$ (solvente orgânico AcOEt) e $0,3 \mathrm{M}$ de 2-etilexanoato de potássio favoreceu a precipitação de clavulanato de potássio com elevado grau de pureza e bom rendimento. Este estudo indicou que as concentrações dos reagentes interferem no rendimento, na estabilidade e na purificação dos cristais obtidos. Este trabalho foi o primeiro a fornecer detalhes sobre os métodos de isolamento, as melhores condições para se efetuar a reação de precipitação do clavulanato de potássio, bem como as análises por RMN realizadas para identificar o clavulanato de potássio obtido. ${ }^{57}$

Vale ressaltar que o AC é uma molécula muito instável com elevadas velocidades de degradação, o que dificulta seu processo de isolamento e purificação. Sua baixa estabilidade em soluções aquosas faz diminuir o rendimento durante as etapas de purificação, como citam Barboza et al.. ${ }^{58,59}$

\section{Mecanismo de ação do ácido clavulânico}

Muitos antibióticos têm ligações químicas hidrolisáveis cuja integridade é fundamental para exercerem atividade biológica. Existem muitos exemplos de enzimas que envolvem a quebra destas ligações vulneráveis, destruindo a atividade do antibiótico. Como as enzimas necessitam apenas de água como cossubstrato, estas podem frequentemente ser excretadas pela bactéria, interceptando os antibióticos, antes que eles entrem em contato com a mesma. O AC é um potente inibidor das Ser- $\beta$-lactamases da classe A. Quando ele é utilizado juntamente com antibióticos $\beta$ lactâmicos, ocorre uma ligação irreversível entre o grupo hidroxila da serina da $\beta$-lactamase e o ácido clavulânico, produzindo um composto estável, inativando a enzima e permitindo assim que o outro antibiótico atue no combate a infecção, ${ }^{11,15,60,61}$ como mostra a Figura 4.
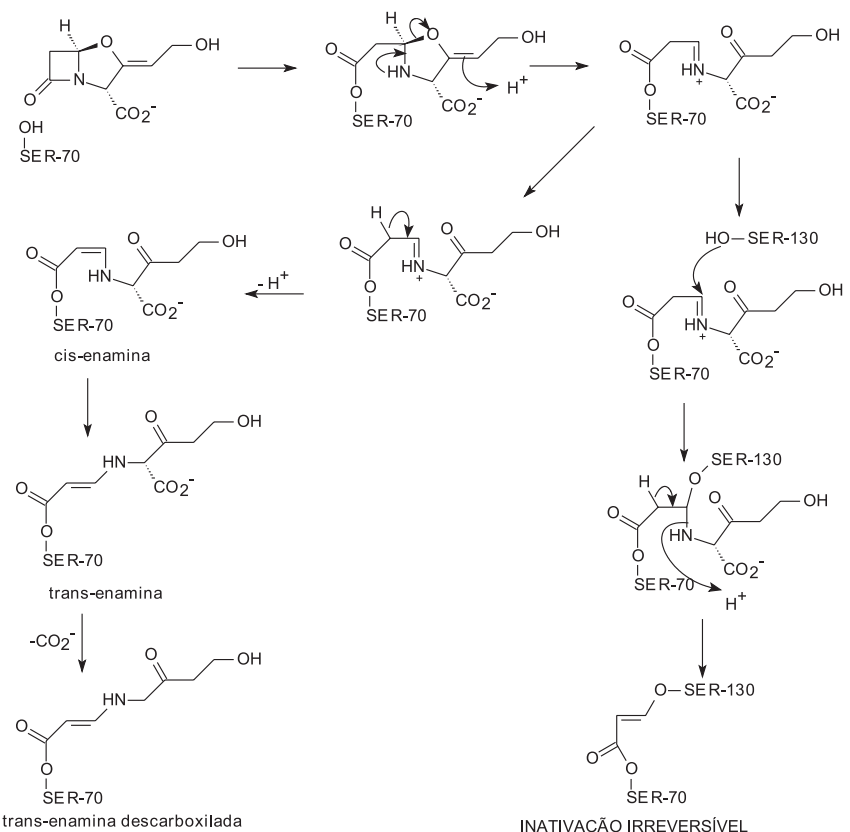

Figura 4. Mecanismo de ação do ácido clavulânico

\section{CEFAMICINA C}

As cefamicinas pertencem a uma importante classe de compostos com atividade antibiótica, isolada no início da década de 70 pela Merck \& Co Inc. e pela Eli Lilly \& Co. O primeiro membro isolado desta família foi a cefamicina C (CefC), produzida por Nocardia lactamdurans $^{62}$ e $S$. clavuligerus ${ }^{63}$ bem como por vários outros actinomicetos. As cefamicinas ${ }^{64}$ diferem das cefalosporinas pela substituição de um hidrogênio, na posição $7 \alpha$ do anel bicíclico, por um grupo metoxila e a cefamicina $\mathrm{C}$ foi o primeiro composto $\beta$-lactâmico a ser isolado a partir de bactéria.

A atividade antibiótica das cefamicinas está relacionada à sua habilidade de se ligar a uma proteína receptora no organismo susceptível e, então, inibir a síntese de sua parede celular. A estrutura $\beta$-lactâmica inibe especificamente a atividade das enzimas transpeptidases. ${ }^{65}$

A CefC foi identificada, primeiramente, como inibidor de síntese de parede celular bacteriana. ${ }^{66}$ Posteriormente descobriu-se que este composto, além de possuir esta atividade inibitória, é resistente à ação das $\beta$-lactamases e que o grupo $7 \alpha$ metoxila é o responsável por esta atividade. Este grupo atua como estabilizador da estrutura do anel $\beta$-lactâmico, reduzindo a sensibilidade à lactamase. ${ }^{65}$ 
Enquanto a CefC é ativa contra organismos Gram-negativos, não é ativa contra os Gram-positivos, assim, esta molécula precisou ser quimicamente modificada para aumentar seu espectro de atividade antibiótica. A troca da cadeia lateral aminoadipil na posição $7 \beta$ da CefC por um grupo tienilacetil proporcionou o efeito desejado, o que resultou no composto semi-sintético $\beta$-lactâmico, cefoxitin. O cefoxitin, produzido pela Merck \& Co Inc., é amplamente usado no tratamento de infecções e na prevenção de infecções pós-operatórias por bactérias resistentes à penicilina. É interessante o fato de que a introdução de um grupo metoxila na posição 6 resulta na perda da atividade biológica. ${ }^{3}$

Além do cefoxitin, outros antibióticos semi-sintéticos são obtidos a partir da cefamicina $\mathrm{C}$, como o cefometazol e o cefotetan, todos com excelente atividade contra bactérias Gram-negativas resistentes aos antibióticos $\beta$-lactâmicos conhecidos. ${ }^{67}$

O cefminox, um antibiótico de terceira geração, foi obtido por uma modificação na posição $7 \beta$ e uma metoxilação da posição $7 \alpha$, por Iwamatsu et al. ${ }^{68}$ no Japão. O cefminox é mais ativo que outras cefamicinas contra enterobactéria e Bacteróides fragilis, exibindo propriedades farmacocinéticas favoráveis. Contudo, muitas dificuldades são encontradas no processo químico da $7 \alpha$-metoxilação. ${ }^{69}$

A descoberta da CefC representa um marco no desenvolvimento dos antibióticos, pois pela primeira vez, uma molécula com atividade antibacteriana mostrou-se resistente a $\beta$-lactamases de bactérias Gram-negativas. A CefC não é utilizada clinicamente, porém é o precursor de vários antibióticos de importância terapêutica, chamados cefâmicos. S. clavuligerus, amplamente estudado por Liras, ${ }^{14}$ é dos mais utilizados industrialmente tendo a capacidade de sintetizar também o AC. Porém diferentemente do AC, sua biossíntese já é conhecida, tendo várias etapas em comum com aquelas da biossíntese das cefalosporinas, incluindo a formação do tripeptídeo ACV como intermediário. ${ }^{14} \mathrm{~A}$ CefC é produzida por grandes empresas farmacêuticas, como Eli Lilly \& Co., Takeda Industries e Otsuka Pharmaceuticals. ${ }^{70,71}$ Para a produção da CefC são utilizados actinomicetos, sendo que apenas a Merck \& Co. Inc. emprega Nocardia lactamdurans, ${ }^{4}$ este antibiótico é produzido por fermentação para depois ser transformado quimicamente, e não se encontra disponível comercialmente nem mesmo sob a forma de reagente.

\section{Biossíntese da cefamicina $\mathrm{C}$}

A biossíntese de antibióticos em culturas de actinomicetos em meios ricos em nutrientes segue um modelo de duas fases, caracterizado por uma fase de rápido crescimento onde se acumula biomassa, seguida da fase de produção dos antibióticos, na qual as enzimas utilizadas na síntese dos mesmos são formadas rapidamente e permanecem ativas por um certo período, até que decaem irreversivelmente. A demanda de oxigênio dissolvido é uma variável crítica nos tanques de fermentação para que se obtenha boa produção de antibiótico. Nas fermentações onde são produzidas a CefC e a cefalosporina $\mathrm{C}$, a redução de oxigênio leva ao acumulo de um dos intermediários, a penicilina $\mathrm{N}$, o que indica a baixa eficiência da conversão deste intermediário no produto final, que requer a introdução de oxigênio molecular. ${ }^{72}$

Na biossíntese das cefamicinas (Figura 5) são utilizados três aminoácidos como precursores, o ácido L- $\alpha$-aminoadípico, a L-cisteína e a L-valina (tripeptídeo ACV), que se unem formando a estrutura $\beta$-lactama. A família das cefamicinas apresenta substituições no C-3 e no C-7. Uma substituição metoxi está sempre presente no C-7 $\alpha$ de todas as cefamicinas e esta substituição confere a elas a capacidade de resistência à enzima $\beta$-lactamase. $O$ grupo metila desta substituição vem do grupo metila da metionina. ${ }^{73} \mathrm{~A}$ segunda substituição no C-7 vem do ácido $\alpha$-aminoadípico. Existe também a substituição carbamoila, que deriva do fosfato de carbamoila. ${ }^{74}$

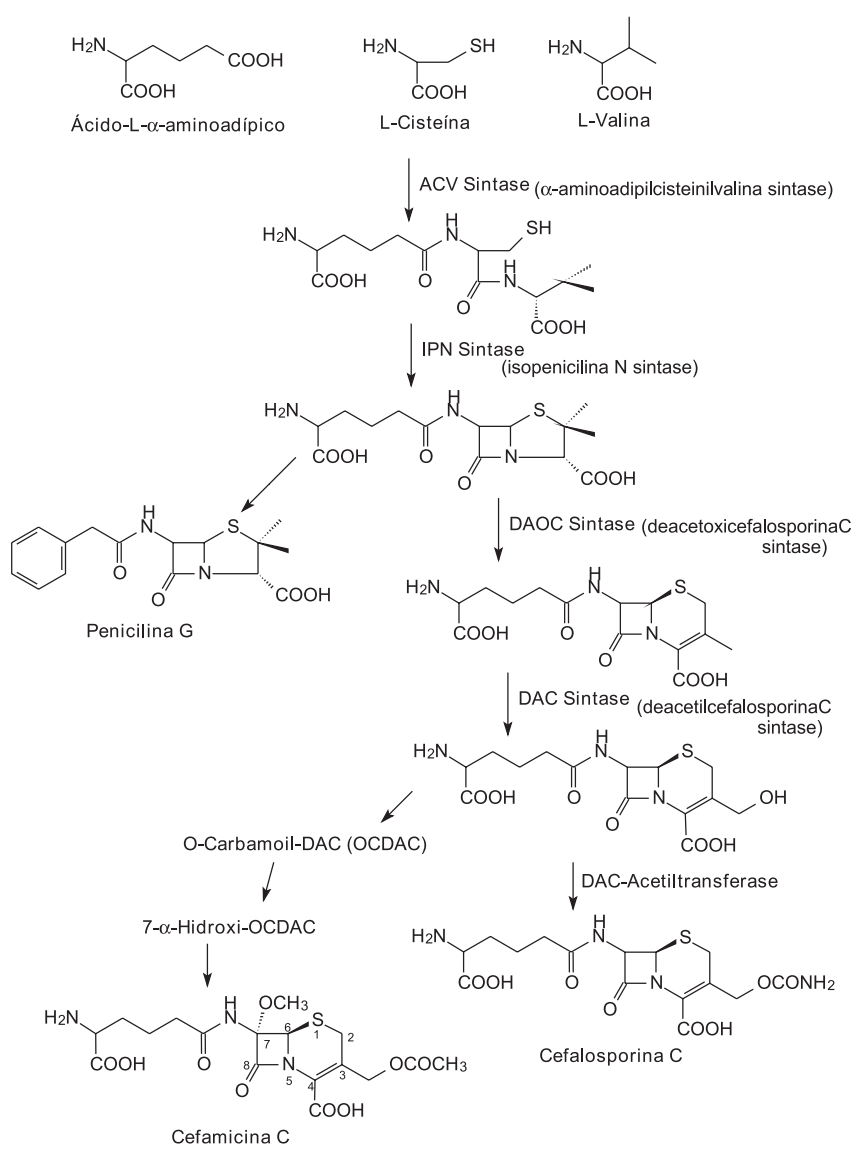

Figura 5. Biossíntese da cefamicina $C$

Kern et al. ${ }^{75}$ propuseram que o tripeptídeo é sintetizado a partir dos aminoácidos individuais, sofrendo posterior ciclização para formar a isopenicilina $\mathrm{N}$, que é convertida em penicilina $\mathrm{N}$ para depois formar o anel de seis membros, a desacetoxicefalosporina. Estes autores sugeriram que a expansão do anel é a etapa limitante na síntese da CefC. A substituição metoxi no C-7 parece acontecer depois da expansão do anel. ${ }^{76}$ Não se sabe quando ocorre a substituição no C-3, mas sabe-se que esta ocorre primeiro e que é justamente ela que distingue as cefamicinas naturais das sintéticas.

\section{Processos de isolamento e purificação da cefamicina C}

Alguns processos de purificação da CefC foram publicados. ${ }^{77,78}$ Schubert ${ }^{78}$ patenteou um processo de reciclagem eficiente que gera a CefC pura e com alto grau de rendimento. Neste processo, o caldo fermentativo tem seu $\mathrm{pH}$ ajustado a um valor entre 1,8-2,5 e em seguida é submetido a uma filtração. O filtrado obtido é aplicado em uma coluna de resina de troca catiônica e a coluna é lavada com água. A fase estacionária é então eluída com solução de $\mathrm{NaCl} 10 \%$. O material coletado tem seu pH ajustado para 7, o qual é então repassado pela coluna. Para que diminua a degradação química em $\mathrm{pH}=7$ abaixa-se a temperatura no processo de purificação. Este procedimento deve ser repetido de $10-15$ vezes. A eficiência deste processo é maior em relação ao processo de adsorção em carvão ativo $^{79}$ e ao processo de troca iônica sequencial. ${ }^{77}$

Já a patente ${ }^{80}$ GB2052502A descreve que após a centrifugação ou filtração do caldo, o filtrado tem seu pH ajustado para 7-8 e então é submetido a uma cromatografia de troca cationnica em resina Diaion PA 406; o material adsorvido é eluído com $\mathrm{NaCl}$ 0,5 M.

Segundo Miller et al., ${ }^{81}$ após a filtração do caldo faz-se uma cromatografia de troca catiônica Dowex 1x2 utilizando como eluente 
$\mathrm{NaCl} 5 \%$. As frações que apresentam atividade são reunidas e seu pH ajustado para 2 com $\mathrm{HCl}$. Nova cromatografia é realizada em resina Dowex 50x2 e como eluente usa-se piridina 2\%. A amostra coletada é concentrada e novamente cromatografada em resina Dowex 1x2, porém desta vez eluída com tampão piridina/ $\mathrm{HCl}(0,1 \mathrm{M}, \mathrm{pH}=5)$. A fração que apresenta atividade é dessalinizada por cromatografia em Bio gel P-2 e ajusta-se o pH para 7. O rendimento é de $66 \%$ e a CefC apresenta $40 \%$ de pureza.

De acordo com Charcosset, ${ }^{82}$ são relatados vários trabalhos utilizando membranas de microfiltração de 0,45 a 0,22 $\mu$ m de diâmetro de poro. Uma das vantagens da utilização dessa técnica de separação é a obtenção de altos valores de recuperação com altos rendimentos, devido à possibilidade da realização de diálise. O processo de ultrafiltração é muito utilizado para a retirada de macromoléculas que interferem nos processos subsequentes. $\mathrm{O}$ autor sugere também que a ultrafiltração pode ser utilizada para a remoção de emulsificação de caldos de antibióticos.

Após a etapa de filtração podem ser utilizadas as técnicas de extração líquido-líquido e/ou cromatográficas, tal como a permeação em gel. De acordo com Barboza et al. ${ }^{58}$ para as cefalosporinas, antibióticos hidrofílicos, a extração líquido-líquido não é muito eficiente devido sua alta solubilidade em água. Neste caso utiliza-se a adsorção em resinas não funcionais do tipo Amberlite XAD-2 para a extração do antibiótico do meio de cultura.

Poucos artigos são encontrados sobre a CefC, e muito pouco se sabe sobre seu isolamento e purificação. Algumas patentes referemse a seu isolamento, mas os procedimentos são descritos superficialmente; além disso, a CefC não está disponível comercialmente, dificultando sua análise quanto à degradação, solubilidade e outras características físico-químicas, as quais poderiam ser úteis durante seu isolamento.

\section{Mecanismo de ação da cefamicina $\mathrm{C}$}

Sabe-se que para a bactéria sobreviver precisa se adaptar a várias condições ambientais, tais como, $\mathrm{pH}$, temperatura e pressão osmótica, para isso é necessário que se tenha uma parede celular robusta. Como a parede celular não é encontrada em células animais, essa é um importante alvo para agentes antimicrobianos, como as penicilinas e cefalosporinas. ${ }^{3}$ Entretanto, é muito difícil atravessar a parede das bactérias, devido à sua formação, que pode agir como uma barreira protetora, por exemplo, a camada exterior pode ter carga positiva ou negativa, dependendo dos triglicerídeos constituintes, um excesso de fosfatidilglicerol pode resultar em uma carga aniônica e, também, um excesso de lisilfosfatidilglicerol pode resultar em uma carga catiônica. Como tanto as penicilinas quanto as cefalosporinas e as cefamicinas apresentam um grupo ácido carboxílico livre, se esse grupo estiver ionizado, o composto será repelido pela membrana celular, como mostra o Esquema 1. Os antibióticos podem conseguir penetrar na parede celular pelos canais de proteína situados na membrana externa, porém muitos desses encontram-se sempre fechados. ${ }^{3}$

A parede celular das bactérias é composta de peptidoglicanos, ou seja, é feita de peptídeos e unidades de açúcar. A estrutura da parede celular consiste de um esqueleto de açúcares, contendo dois tipos de açúcares, o ácido $\mathrm{N}$-acetilmurâmico (NAM) e a N-acetilglucosamina (NAG). As cadeias de peptídeo são ligadas ao NAM e, no passo final da biossíntese da parede celular, essas cadeias de peptídeos se ligam pela substituição da D-alanina de uma cadeia pela glicina de outra cadeia. A enzima responsável pela reação de ligação cruzada é conhecida como transpeptidase (Esquema 2). ${ }^{3}$

Esse é o passo final da reação cruzada que é inibido pelas penicilinas e cefalosporinas, de forma que a estrutura da parede celular não fique unida. Como resultado a parede celular torna-se fraca, uma vez

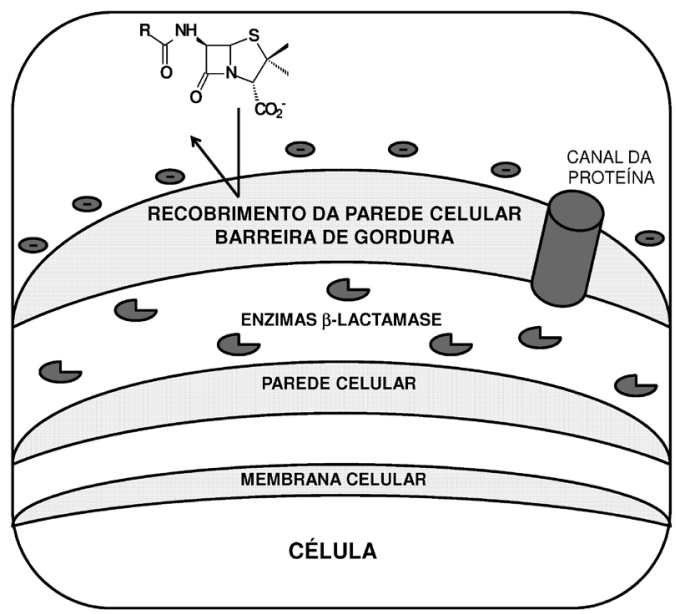

Esquema 1. Esquema da parede celular de uma bactéria. Adaptado da ref. 3

que a concentração salina dentro da célula é maior do que fora, com isso a água penetra na célula, essa fica inchada e acaba se rompendo. ${ }^{3}$ Esse processo pode ser observado no Esquema 2.

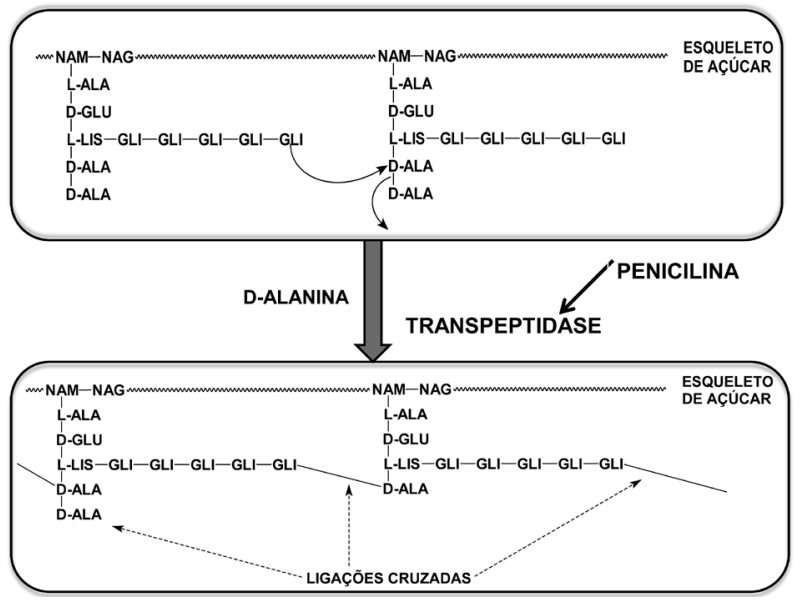

Esquema 2. Esquema de formação da ligação cruzada para construção da parede celular de bactérias. Adaptado da ref. 3

Existe uma proposta em que a penicilina apresenta a mesma conformação da porção da cadeia de aminoácido D-Ala-D-Ala envolvido na reação cruzada. Como este é o centro de reação responsável pela transpeptidase, essa é uma teoria bastante interessante, uma vez que se acredita que por um erro da enzima a unidade D-Ala-D-Ala é substituída por moléculas de penicilina. Uma vez que o antibiótico se encontra no sítio ativo, a reação enzimática ocorre com a penicilina. ${ }^{3}$

No mecanismo normal, a ligação amida entre as duas unidades alanina é dividida. A unidade alanina terminal sai do sítio ativo, deixando a cadeia peptídica ligada ao mesmo. A glicina terminal da cadeia pentaglicil entra no sítio ativo e forma uma ligação peptídica com o grupo alanina, removendo o outro grupo alanina do sítio. ${ }^{3}$

A enzima pode atacar o anel $\beta$-lactâmico da penicilina e abrir o anel da mesma forma que é feito com a ligação amida. Entretanto, como a penicilina é cíclica, essa não é dividida e nada deixa o sítio ativo. Subsequentemente, a hidrólise do grupo acil não ocorre, provavelmente porque a glicina não é capaz de chegar até o sítio de reação, pois a molécula de penicilina impede seu acesso, como pode ser visto no Esquema 3. ${ }^{3}$ Entretanto, ainda existem dúvidas quanto a essa teoria uma vez que, por exemplo, a 6-metilpenicilina é um análogo bastante próximo à D-Ala-D-Ala (Figura 6) e por isso deveria se encaixar melhor no sítio ativo e ser mais ativa, mas, pelo contrário, é menos ativa. ${ }^{3}$ 


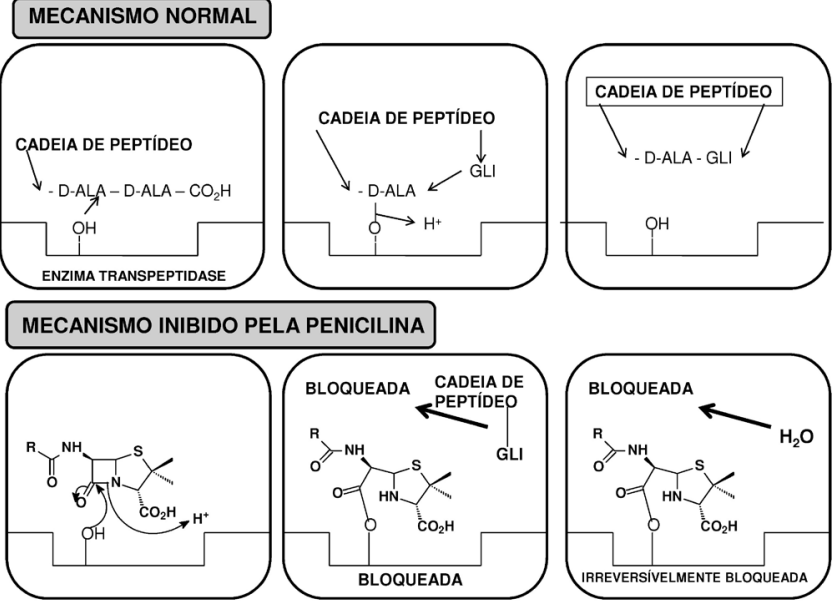

Esquema 3. Mecanismo de ação normal e mecanismo inibido pela molécula de penicilina. Adaptado da ref. 3

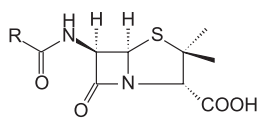

Penicilina

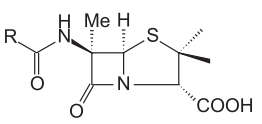

6-MetilPenicilina

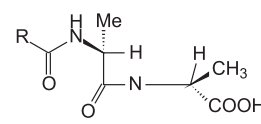

Acil-D-Ala-D-Ala
Figura 6. Estruturas da penicilina, da 6-metilpenicilina e da Acil-D-Ala-D-Ala

Existe ainda uma proposta alternativa onde, na verdade, a penicilina não se liga ao sítio ativo, mas se liga a um sítio vizinho e isso impediria o acesso dos reagentes normais ao sítio ativo - isso é conhecido como efeito guarda-chuva e pode ser visto no Esquema 4. Mesmo que um grupo nucleofílico ataque o anel $\beta$-lactâmico, a penicilina permanece ligada irreversivelmente, bloqueando o acesso ao sítio ativo permanentemente. ${ }^{3}$

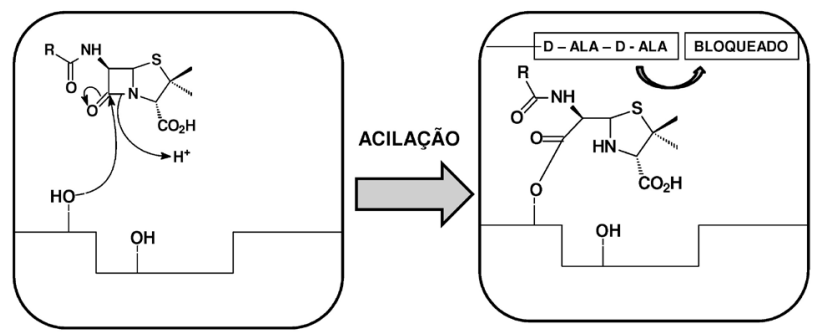

Esquema 4. Mecanismo de ação alternativo da penicilina (efeito guardachuva). Adaptado da ref. 3

\section{CONCLUSÕES}

Os antibióticos, de maneira geral, estão, estiveram ou, provavelmente, estarão presentes na vida de todos nós. A descoberta da penicilina, durante a $2^{\mathrm{a}}$ Guerra Mundial foi o que proporcionou a cura para muitos soldados que, sem ela, teriam pouca chance de sobreviver.

Existem vários grupos de pesquisa em todo o mundo estudando os antibióticos $\beta$-lactâmicos, quer seja para compreender as etapas ainda desconhecidas da biossíntese desses compostos, quer seja para tentar isolar novos compostos bioativos a partir de linhagens produtoras de antibióticos $\beta$-lactâmicos ou, ainda, tentando melhorar a produção e/ou os processos de produção destes compostos. Qualquer que seja a linha de pesquisa, todas trazem informações valiosas e que, sem dúvida, enriquecem o conhecimento a respeito destes compostos.

\section{AGRADECIMENTOS}

À FAPESP (processos 04/15540-1, 05/55079-4 e 06/59474-8), ao CNPq e à CAPES pelo apoio financeiro.

\section{REFERÊNCIAS}

1. Belter, P. A. Em Comprehensive Biotechnology; Moo-Young, M., ed.; Pergamon Press: New York, 1985, vol.2, p. 473-480.

2. Kieser, H. M.; Bibb, K. F.; Buttner, M. J.; Chater, K. F.; Hopwood, D. A.; Practical Streptomyces Genetics, The John Innes Foundation: England, 2000.

3. Patrick G. L.; An Introduction to Medicinal Chemistry, $2^{\text {nd }}$ ed., University Press: Oxford, 2001.

4. Demain, A. L.; Elander, R. P.; Antonie van Leeuwenhoek 1999, 75, 5.

5. McGowan, S. J.; Bycroft, B. W.; Salmond, G. P. C.; Trends Microbiol. 1998, 6, 203.

6. Elander, R. P.; Appl. Microbiol. Biotechnol. 2003, 61, 385.

7. Pelczar Jr, M. J.; Chan, E. C. S.; Krieg, N. R.; Microbiologia Conceitos e Aplicações, $2^{a}$ ed., Makron Books do Brasil Ltda: São Paulo, 1997.

8. Rolinson, G. N.; Rev. Infect. Dis. 1991, 13, 5727.

9. Brown, A. G.; Butterworth, D.; Cole, M.; Hanscomb, G.; Hood, J. D.; Reading, C.; Rolinson, G. N.; J. Antibiot. 1976, XXIX, 668.

10. Saudagar, P. S.; Survase, A. S.; Singhal, R. S.; Biotechnol. Adv. 2008, 26,335 .

11. Buynak, J. D.; Biochem. Pharmacol. 2006, 71, 930.

12. Payne, D. J.; Cramp, R.; Winstanley, D. J.; Knowles, D. J. C.; Antimicrob. Agents Chemother. 1994, 767.

13. Barrero, E.; Resumos da Conferência Nacional de Ciência, Tecnologia e Inovação, Brasília, Brasil, 2001.

14. Liras, P.; Rodríguez-Garcia, A.; Appl. Microbiol. Biotechnol. 2000, 54, 467.

15. Baggaley, K. H.; Brown, A. G.; Schofield, C. J.; Nat. Prod. Rep. 1997, 14, 309.

16. Mayer, A. F.; Anspach, F. B.; Deckwer, W. D.; Bioseparation 1996, 6, 25.

17. Hoban, D. J.; Bouchillon, S. K.; Johnson, J. I.; Zhanel, G. G.; Buttler, D. L.; Sounders, K. A.; Int. J. Antimicrob. Agents 2003, 21, 425.

18. Legnani, D.; Diag. Microbiol. Infect Dis. 1997, 27, 41.

19. Adjei, O.; Opoku, C.; Int. J. Antimicrob. Agents 2004, 24, 32.

20. Oringer, R. J.; J. Evid. Based Dent. Pract. 2003, 3, 77.

21. Baumgartner, J. C.; Xia, T.; J. Endod. 2003, 29, 44.

22. Attar, A.; Flourié, B.; Rambaud, J. C.; Franchisseur, C.; Ruszniewski, P.; Bouhnik, Y.; Gastroenterology 1999, 117, 794.

23. Finlay, J.; Miller, L.; Poupard, J. A.; J. Antimicrob. Chemother. 2003, 52, 18.

24. Severin, A.; Severina, E.; Tomasz, A.; Antimicrob. Agents Chemother. 1997, 41, 504.

25. Romero, J.; Liras, P.; Martin, J. F.; Appl. Environ. Microbiol. 1986, 52, 892.

26. Townsend, B. C. A.; Ho, M.; J. Am. Chem. Soc. 1985, 107, 1065; Townsend, A.C.A.; Ho, M.; J. Am. Chem. Soc. 1985, 107, 1066.

27. Romero, J.; Liras, P.; Martin, J. F.; Appl. Microbiol. Biotechnol. 1988, 27, 510 .

28. De la Fuente, J. L.; Martín, J. F.; Liras, P.; Biochem. J. 1996, 320, 173.

29. Valentine, B. P.; Bailey, C. R.; Doherty, A.; Morris, J.; Elson, S. W.; Baggaley, K. H.; Nicholson, N. H.; J. Chem. Soc., Chem. Commun. 1993, 1210.

30. Elson, S. W.; Baggaley, K. H.; Gillet, J.; Holland, S.; Nicholson, N. H.; Sime, J. T.; Woroniecki, S. R.; J. Chem. Soc., Chem. Commun. 1987, 1736; Elson, S. W.; Baggaley, K. H.; Gillet, J.; Nicholson, N. H.; Sime, J. T.; Woroniecki, S. R.; J. Chem. Soc., Chem. Commun. 1987, 1739.

31. Elson, S. W.; Baggaley, K. H.; Fulston, M.; Nicholson, N. H.; Tyler, J. W.; Edwards, J.; Holms, H.; Hamilton, I.; Mousdale, D. M.; J. Chem. Soc., Chem. Commun. 1993, 1211; Elson, S. W.; Baggaley, K. H.; Davison, M.; Fulston, M.; Nicholson, N. H.; Risbridger, G. D.; Tyler, J. W.; J. Chem. Soc., Chem. Commun. 1993, 1212.

32. Salowe, S. P.; Marsh, E. N.; Townsand, C. A.; Biochemistry 1990, 29, 6499. 
33. Nicholson, N. H.; Baggaley, K. H.; Cassels, R.; Davison, M.; Elson, S. W.; Fulston, M.; Tyler, J. W.; Woroniecki, S. R.; J. Chem. Soc., Chem. Commun. 1994, 1281

34. Bersanetti, P. A.; Barboza, M.; Hokka, C. O.; Araujo, M. L. G. C.; Resumos do XIII SINAFERM (Simpósio Nacional de Fermentações), Teresópolis, Brasil, 2000.

35. Bersanetti, P. A.; Almeida, R. M. R. G.; Barboza, M.; Araujo, M. L. G. C.; Hokka, C. O.; Biochem. Eng. J. 2005, 23, 31.

36. Mayer, A. F.; Hartmann, R.; Deckwer, W. D.; Chem. Eng. Sci. 1997, 52, 4561.

37. Haginaka, J.; Nakagawa, T.; Uno, T.; Chem. Pharm. Bull. 1981, $29,3334$.

38. Haginaka, J.; Yasuda, H.; Uno, T.; Nakagawa, T.; Chem. Pharm. Bull. 1985, 33, 218

39. Finn, M. J.; Harris, M. A.; Hunt, E.; Zomaya, I. I.; J. Chem. Soc. Perkin Trans. I 1984, 1345.

40. Cole, M.; Howarth, T. T.; Reading, C.; PS 1,508,977 1978.

41. Box, S. J.; US pat. 4,072,569 1978.

42. Box, S. J.; $P S$ 1,563,103 1980.

43. Fleming, I. D.; Noble, D.; Wall, W. F.; PS 1,543,563 1979.

44. Fleming, I. D.; Noble, D.; Wall, W. F.; US pat. 4,367,175 1983.

45. Cook, M. A.; WO 051421997.

46. Kim, J. K.; Choi, N. H.; Choi, G. S.; Lee, D. W.; WO 341941995.

47. Cardoso, J. P.; WO 98/42858 1998.

48. Capuder, E.; US pat. 6,180,782B1 2001.

49. Capuder, E.; US pat. 2001/0007761A1 2001.

50. Capuder, E.; US pat. 5,780,274 1998.

51. Simon, R.; US pat. 6,172,221 2001.

52. Callewaert, G. L.; US pat. 5,786,351 1998.

53. Butterworth, D.; Biotech. Ind. Antibiot. 1984, 22, 225.

54. Videira, M.; Aires-Barros, M. R.; J.Chromatogr., A 1994, 668, 237.

55. Brites, L. M.; Hirata, D. B.; Pasotto, M. B.; Hokka, C. O.; Resumos do XX Congresso Mercosul de Engenharia Química (EMPROMER), Costa Verde, Brasil, 2005.

56. Silva, C. S.; Bovarotti, E.; Rodrigues, M. I.; Hokka, C. O.; Barboza, M.; Bioprocess Biosyst. Eng. (2008), doi:10.1007/s00449-008-0285-6.

57. Hirata, D. B.; Oliveira, J. H. H. L.; Leão, K. V.; Rodrigues, M. I.; Ferreira, A. G.; Giulietti, M.; Barboza, M.; Hokka, C. O.; Sep. Purif. Technol. 2009, 66, 598.

58. Barboza, M.; Almeida, R. M. R. G.; Hokka, C. O.; Ind. Eng. Chem. Res. 2002, 41, 5789; Barboza, M.; Almeida, R. M. R. G.; Hokka, C. O.; Bioseparation 2002, 10, 221; Barboza, M.; Maugeri Filho, F.; Hokka, C. O.; Bioprocess. Biosyst. Eng. 2002, 25, 193.
59. Barboza, M.; Almeida, R. M. R. G.; Hokka, C. O.; Biochem. Eng. J. 2003, 14, 19.

60. Charnas, R. L.; Fisher, J.; Knowles, J. R.; Biochem. 1978, 17, 2185.

61. Charnas, R. L..; Knowles, J. R.; Biochem. 1981, 20, 3214.

62. Stapley, E. O.; Jackson, M.; Hernandez, S.; Zimmerman, S. B.; Currie, S. A.; Mochale, S.; Mata, J. M.; Woodruff, H. B.; Henlin, D.; Antimicrob. Agents Chemother. 1972, 2, 122.

63. Nagajarian, R.; Boeck, L. D.; Gorman, M.; Hamill, R. L.; Higgins, C. E.; Hoehn, M. M.; Stark, W. M.; Whitney, J. G.; J. Am. Chem. Soc. 1971, 93, 2310

64. Fukase, H.; Hasegawa, T.; Hatano, K.; Iwasaki, H.; Yoneda, M.; J. Antibiot. 1976, 113

65. Omstead, D. R.; Hunt, G. R.; Buckland, B.C.; Comprehensive biotechnology, Pergamon Press Inc.: USA, 1985.

66. Daust, D. R.; Onishi, H. R.; Wallick, H.; Hendlin, D.; Stapley, E. O.; Antimicrob. Agents Chemother. 1973, 3, 254.

67. Park, Y. S.; Momose, I.; Tsunoda, K.; Okabe, M.; Appl. Microbiol. Biotechnol. 1994, 40, 773.

68. Iwamatsu, K.; Inouye, S.; Tsuruoka, T.; Mizutani, K.; Omoto, S.; Ogino, H.; Miyauch, K.; Watanabe, T.; Niida, T.; J. Antibiot. 1983, 36, 229.

69. Kim, J. K.; Kang, H.; Chae, J. S.; Park, Y. H.; Choi, Y. J.; FEMS Microbiol. Lett. 2000, 182, 313.

70. http://www.expresspharmapulse.com/20020131/research1.shtml, acessada em ???? 2002

71. Devi, S.; Sridhar, P.; World J. Microbiol. Biotechnol. 1999, 15, 185

72. Leitão, A. L.; Enguita, F. J.; Martín, J. F.; J. Biotechnol. 1997, 58, 39.

73. Whitney, J. G.; Brannon, D. R.; Mabe, J. A.; Wicker, K. J.; Antimicrob. Agents Chemother. 1972, 1, 247.

74. Brewer, S. J.; Boyle, T. T.; Turner, M. K.; Biochem. Soc. Trans. 1977, 5, 1026.

75. Kern, B. A.; Hendlin, D.; Inamine, E.; Antimicrob. Agents Chemother. 1980, 17, 674.

76. O’Sullivan, J.; Abraham, E. P.; Biochem. J. 1980, 186, 613.

77. Pines, S.; Jamieson, N. C.; Kozlowski, M. A.; US pat. 3,733,320 1973.

78. Schubert, P. F.; US pat. 4,196,285 1980.

79. Pines, S.; US pat. 3,983,108 1976.

80. Kamogashira,T.; Nishida, T.; Sugawara, M.; Nihno, T.; Takegata, S.; UK pat. 2,052,502 1981.

81. Miller, T. W.; Goegelman, R. T.; Weston, R. G.; Putter, I.; Wolf, F. J.; Antimicrob. Agents Chemother. 1972, 2, 132.

82. Charcosset, C.; Biotechnol. Adv. 2006, 24, 482. 